\title{
Special features of general practice (primary care) and ethical implications
}

\author{
John Fry General practitioner, Kent
}

\section{Author's abstract}

In all systems of health care there are certain essential levels of care and service. These take the form of self-care within the family unit; primary professional care by general medical nursing or social practitioners within a local neighbourhood; general specialist care in a district and super-specialist care in a region. Each of these has its own special roles and responsibilities and each is considered in this paper.

\section{Introduction}

General practice (primary care) is a distinct medical specialty with its own special features and methods that influence ethical concepts and behaviour. What distinguishes it from other specialities is its direct access and availability of the doctor to the patient. It is the first-contact primary care, where the patient brings an undefined and unclassified package of problems for the general practitioner to assess, diagnose and manage. The work involves care for a relatively small number of patients $(2000-2500)$ per general practitioner and the population is usually static. Long-term care is the rule rather than the exception. The practitioner cares for, and often comes to know two or three generations of families.

The morbidity and mortality patterns are those that can be expected to occur in a population of 2000-2500 persons, no more and no less. The disorders and problems are common ones, with rare diseases seldom occurring. With nine out of ten consultations in general practice being managed by the practitioner, the process of referral to, and collaboration with, other medical and paramedical specialities is an important role in co-ordinating and manipulating the available services for the good of the patient. In many health care systems, including the British National Health Service, the general practitioner is an independent contractor able to organise and to manage his work as he thinks best and without too many directives. The ways in which the general practitioner is paid will influence the ways in which he works. Fees-for-services will encourage more consultations and more investigations than in a capitation or salaried system.

Taking these special features as focal points certain ethical issues relate to all of them.

\section{Accessibility-availability}

\section{WHOSE PATIENT ?}

In the British National Health Service persons register with a general practitioner. This provides a legal basis for defining a doctor-patient relationship. In other systems patients tend to 'shop around' and ethical rules are necessary to avoid confusion and dangers that can occur when more than one doctor is involved in treating a patient at the same time without close professional collaboration.

\section{OUT OF HOURS COVER}

In theory the general practitioner is responsible for providing a continuous 24 -hour service. This is not possible. There have to be arrangements for sharing the care with other colleagues.

The best way to organise such out of hours cover is by a regular rota shared among practitioners in the same practice or with neighbouring practices in the area. All the practitioners are known to one another and they are familiar with the local community and the local services that are available.

In many countries commercial deputising services have been created to provide out of hours cover in primary care. The doctors are usually young hospital doctors who visit patients in their homes when called in an emergency. They tend to be untrained for and inexperienced in general practice and are unfamiliar with the local community and the local health services. They are unknown to the patient and to the doctor who employs them.

\section{APPOINTMENT SYSTEMS}

These and other barriers have arisen which make contact between doctor and patient difficult. An essence of good general practice is speedy access to the doctor. Appointment systems, which now seem to be the rule in British general practice, have been introduced to provide a more manageable organisation. However, they must ensure that any patient is able to consult the doctor within 24 hours, if his or her condition so requires.

In addition to appointment systems the patient now has to overcome the barrier of a secretaryreceptionist before he is able to meet his doctor. It is important therefore that the secretary-receptionist is sensitive to the patient's needs, anxiety and personality in acting in the front line of medical practice. 


\section{FIRST CONTACT CARE}

In his role in providing such care the general practitioner now tends to work as a member of the primary health care team that includes, among others, his partners, nurses, health visitors (public health nurses), social workers, secretary-receptionists and doctors' wives.

In addition, if the practice is involved in teaching, then there are trainee-practitioners and undergraduate medical students who may be involved in seeing and treating the patient.

The ethical issues involve the degree of sharing and delegation among the team. The underlying principle must be that no one in the team ought to be expected to undertake care and treatment for which he or she has not been trained, but rather in which he or she is experienced and by which he or she is covered by law.

\section{Small and static community}

Working and living as a member of a small practice population the doctor must take very special care to observe the ethics of professional doctor-patient relations. He must look upon his patients as friends but not encourage and develop too close and familiar personal relations. By so doing this could expose him to many unnecessary risks.

In such a small and static population strict confidentiality is all important. Not only must confidentiality be maintained within the practice team, but professional confidences must not be divulged to members of the patient's near and extended family without permission. The doctor's own family has to be considered. It is natural for him to discuss his work with his wife and family, but patient's confidences must be maintained at all times in all places.

There is a nice line which the general practitioner has to tread. He has to be aware of and assume appropriate social and community responsibilities as well as interpreting wisely and widely his roles as a family doctor. He must beware of becoming too involved in the lives of his community and in the lives of families for whom he cares. Some communities and some families do not wish pastoral over-involvement from some general practitioners.

Home visiting is a part of general practice which has declined with social and medical advances. It is still needed for the house-bound, the terminally ill and those with acute medical conditions. Such visiting is a privilege for the doctor and must be treated with respect. Requests for home visits are one of the most frequent causes of friction between patients and general practitioners. Sometimes the practitioner does not consider a home visit necessary, and this can cause the patient a great deal of annoyance, so leading to a breakdown of good doctorpatient relations.

\section{DRUGS AND RECORD KEEPING}

The volume of drugs prescribed by doctors increas each year as does the price of these drugs. average, each person in Britain receives $6 \% 3$ prescription scripts per year at an annual cost of $£$ per person. It is difficult to decide ethically how many of these prescriptions are really necessary and how many are useful to the patient's welfare. It difficult often for the doctor to resist the patient demands for and expectations of drugs.

The British National Health Service recorw designed for use in general practice are scarce conducive to good record-keeping. They are te small to include much detail and their folders a $\vec{\omega}$ not large enough to contain life-long reports investigations and specialists' reports. Nevertheles, good practice demands that good records are kepr and it is the doctor's duty to ensure that this is $\overrightarrow{\$ S}$ despite the constraints of the methods available.

\section{ILLNESS AND DEATH}

The general practitioner is a specialist in the mo bidity of common physical, emotional and socki problems. He also has to become expert in the early diagnosis of major illnesses and in their continuifo care in collaboration with other specialists. He has to share and accept such responsibilities and realise the limits of his experience and abilities.

One third of all persons still die in their own hom with the general practitioner intimately involved the care of the dying and in the grief and the bereavement processes that follow. The management of the terminal illnesses and care of the persogs dying from them is very much a responsibility the general practitioner shares with home nurses a af social workers in the community and with other specialists in the hospital.

The dying patient must be relieved and coinforted. There should be no limits to the efforts that should be made to comfort the dying and his fami\&. There are no hard and fast rules that can be defined and followed universally. Each person and eagh family must be cared for individually with sense and sensitivity. There can be no rules that state that dying person must be told the truth, the whole trutbb and nothing but the truth about his illness. There can be no rules about the detailed support thet individuals and families need in helping someos through the whole process of dying, death and tie aftermath.

Potent drugs are now available for the relief $\frac{\text { ब⿰ }}{\mathrm{f}} \mathrm{f}$ pain and other discomforts. These should be use effectively and efficiently to ease suffering. Thay must not be used indiscriminately for the purposes of euthanasia. They must not, however, be used over enthusiastically by physicians to prolo unnecessary suffering and distress.

After the patient's death the physician has continuing responsibilities to the family in distre The family must be made to appreciate that 
physician is ready and available to offer comfort and support during the drawn-out process of grief and bereavement.

RELATIONS BETWEEN GPS AND OTHER SPECIALISTS

The general practitioner is the chief link between the patient and the other medical and surgical specialists. Except in a system where there is free access to all specialists, it is usually through being referred by a GP that the patient is seen by a specialist. The general practitioner has to decide when a referral is necessary and to whom the patient should be referred.

The specialist, for his part, must respect his role as a consultant and understand that the patient should be returned to the GP, with a report, once his special tasks have been completed. The specialist ought not to take over the long-term care of the patient except where this has been agreed with the general practitioner.

The patient may be referred to a specialist who is employed in a health care system where no fees are paid or he may be referred to a specialist who takes only fee-paying patients. These may be covered by pre-paid insurance. However, whatever the system the same ethical rules should apply.

\section{Conclusion}

General practice (primary care), therefore, is an essential and inevitable level of care in all health care systems. It has been seen that it is a special field of work with its own special roles and features. The ethical implications relate closely to these roles and functions and should form an important part in any general practitioner's training whether or not he finally practises in the public or private sector.

\section{Editor's note}

This is the first of a series of articles on ethics in general practice. 